\title{
Influence of Unbound Materials Input Level on Pavement Performance using MEPDG
}

\section{دراسة تأثير مستوي ادخال خواص طبقة الأساس علي أداء الرصف باستخدام دليل تصميم الرصف الميكانيكي التجريبي}

\author{
R. Abd El-Hakim ${ }^{1}$, S. El-Badawy ${ }^{2}$, A. Gabr ${ }^{3}$, A. Azam ${ }^{3}$ \\ ${ }^{1}$ Assistant professor, Public Works Engineering Department, Faculty of \\ Engineering, Tanta University, E-mail: ragaa.abdelhakim@f-eng.tanta.edu.eg \\ ${ }^{2}$ Associate professor, Public Works Engineering Department, Faculty of \\ Engineering, Mansoura University,E-mail: sbadawy@mans.edu.eg \\ ${ }^{3}$ Assistant professor, Public Works Engineering Department, Faculty of \\ Engineering, Mansoura University
}

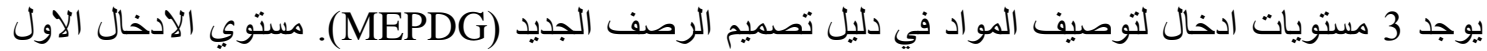

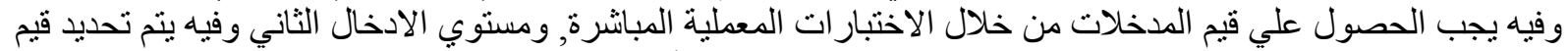

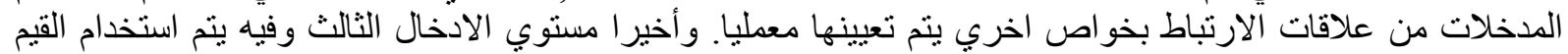

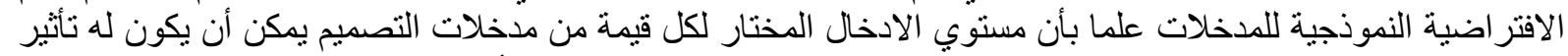

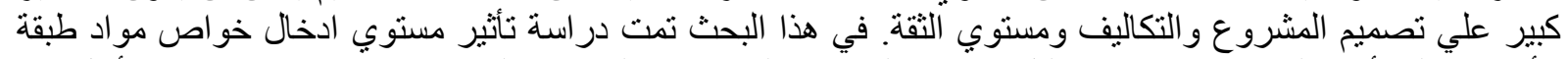

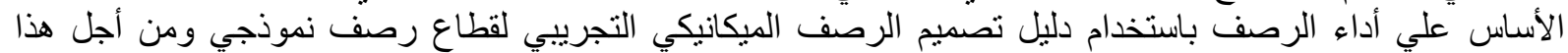

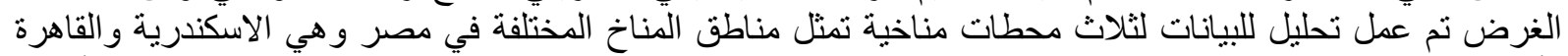

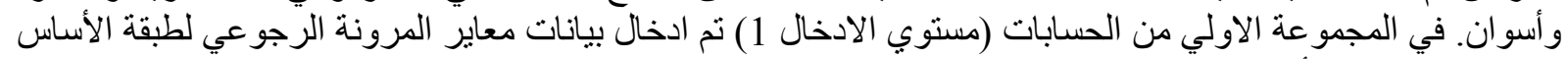
المقاس معطليا علي أساس قيم معاملات الارتباط

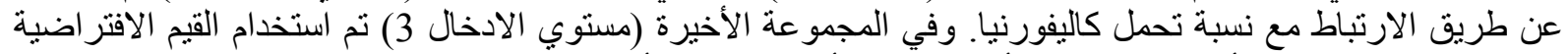

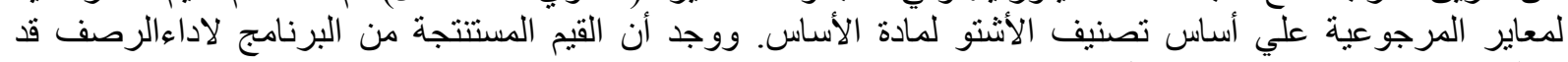
اختلفت مع اختلاف مستوي الادخال.
\end{abstract}

\begin{abstract}
:
For material characterization, the new Mechanistic Empirical Pavement Design Guide (MEPDG) has 3 input levels. Level 1 input values must be obtained through direct laboratory testing. Level 2 inputs are determined by the application of correlations with other material properties. Finally, Level 3 inputs are simply typical default values. The level chosen for each design input parameter, however, may have a significant effect on project design, costs, and reliability. In this paper, the influence of the unbound granular base material characterization input level on pavement performance as predicted by MEPDG for a typical flexible pavement section was investigated. For this purpose, analyses were made for three weather stations representing different climatic regions in Egypt: Alexandria, Cairo and Aswan. For the typical pavement system, level 1 data for the resilient modulus based on measured laboratory values $\left(\mathrm{k}_{1}, \mathrm{k}_{2}\right.$, and $\mathrm{k}_{3}$ elastic response coefficients) were used for the first set of MEPDG runs. The second set of computer simulation runs were conducted using correlation from California Bearing Ratio (CBR) values. The final set of runs, utilized default resilient modulus values of the unbound base material based on the AASHTO class. MEPDG predicted pavement distresses for the three input levels were compared and the results showed variation in performance due to the change in the input level.
\end{abstract}

\section{Keywords}

$\mathrm{Mr}, \mathrm{CBR}$, MEPDG, performance, $\mathrm{k}_{1}, \mathrm{k}_{2}, \mathrm{k}_{3}$

\section{Background:}

Resilient modulus (Mr) is an important engineering parameter for mechanistic and empirical pavement design methods. It is an indication of the elastic behaviour as well as the load carrying ability of pavement materials 
under cyclic traffic loads. The resilient modulus depends on various factors such as deviator stress, density, and moisture content. George (2004) and Mohammed et al. (1999) reported that the most influential soil index properties with respect to resilient modulus were moisture content, degree of saturation, material passing \#200 sieve, liquid limit, plasticity index and density. For example, Thompson and LaGrow (1988) proposed relation for conventional flexible pavement design purposes as shown in Equation 1. Woolstrum (1990) prepared mathematical equation (Equation 2) to estimate the resilient modulus from the soil group index based on the soil classification. Furthermore, Janoo et al. (1999) established a range of typical resilient modulus values for subgrade types.

$$
\begin{aligned}
& M_{r}(O P T)=4.46+0.098 C+0.119 P I \\
& M_{r}=100\left[B_{0}+B_{1}(G I)+B_{2}\left(G I^{2}\right)+\right. \\
& \left.B_{3}\left(G I^{3}\right)+B_{4}\left(G I^{4}\right)\right]
\end{aligned}
$$

Where:

$\mathrm{M}_{\mathrm{r}}=$ Resilient modulus at optimum moisture content (OMC) and at 95\% compaction

$\mathrm{C}=$ less than 2 micron clay content $(\%)$

$\mathrm{PI}=$ Plasticity index $(\%)$

$\mathrm{GI}=$ group index

$\mathrm{B}_{0}, \mathrm{~B}_{1}, \mathrm{~B}_{2}, \mathrm{~B}_{3}, \mathrm{~B}_{4}=$ regression parameters

Some correlation equations have been reported to estimate the resilient modulus from California Bearing Ratio (CBR) and R value. Heukelom and klomp (1962) proposed an equation between the resilient modulus and CBR as presented in Equation 3. Similar equation relating the $M_{r}$ with $R$ value was developed by the Asphalt Institute (1982) as shown in Equation 4.

$$
\begin{aligned}
& M_{\mathrm{r}}(\mathrm{psi})=1500 \mathrm{CB} \\
& \mathrm{M}_{\mathrm{r}}(\mathrm{psi})=\mathrm{A}+\mathrm{B} \text { (Rvalue) }
\end{aligned}
$$

Where:

$\mathrm{A}=772$ to 1155
$\mathrm{B}=369$ to 555

$\mathrm{R}$ value $=$ Stablometer value, Ibs

Witczak et al. (2000) studied the influence of changes in relative moisture content either side of optimum moisture content (OMC) on the resilient modulus of cohesive soils for materials compacted at maximum dry density (MDD). It was observed that even low variations in moisture content resulted in significant changes in resilient modulus.

The Mechanistic-Empirical Pavement Design Guide (MEPDG) has been designed to update the 1993 American Association of State Highway and Transportation Officials (AASHTO) for pavements design, which was first released in 2004 and approved by AASHTO in 2008 (AASHTO, 2008). New software was released in 2011 to be a ready-product to the MEPDG, which is known as DARWin-ME software for pavement design and analysis. The MEPDG software offers the computation of the structural responses (stresses, strains, and deflections), within a pavement system, using the pavement response model JULEA multi-layer elastic analysis for flexible pavements (ARA, 2004; AASHTO, 2008; El-Bradawl et al., 2012). The MEPDG software also allows the Enhanced Integrated Climatic Model (EICM) for calculating the moisture and temperature variations within the pavement structure. Then, the pavement distresses (i.e., rutting, cracking, and roughness) can be predicted via empirical models from the mechanistically computed strains and deformations.

In the MEPDG software, there are three hierarchical traffic input levels for the materials and traffic based on the importance of the project and the availability of data (AASHTO, 2008; ARA, 2004; El-Badawy et al., 2011a). For the traffic inputs: in level 1, detailed knowledge of historical load, volume, and classification data at or near the project location are required. Level 2 needs regional axle load spectra instead of site- 
specific data. Level 3 requires estimates of truck traffic volume data and state-wide default axle load spectra with no sitespecific knowledge of traffic characteristics at the project site.

For the characterization of the Hot Mix Asphalt (HMA), three different hierarchical input levels are permitted in the MEPDG software, depending on the available data for both asphalt mixes and asphalt binders (ARA, 2004; El-Badawy et al., 2012). For binder characterization, levels 1 and 2 require laboratory measurements based on the binder grading system. Laboratory-measured binder shear modulus $\left(\mathrm{G}^{*}\right)$ and phase angle $(\delta)$ values at different temperatures and one angular loading frequency of $10 \mathrm{rad}=\mathrm{s}(1.59 \mathrm{~Hz})$ are required if the Superpave performance grade is utilized. On the other hand if conventional binder grades are used, traditional asphalt testing, such as penetration, ringand ball softening point, absolute and kinematic viscosities, and Brookfield, are implemented in the software. For the default Level 3 binder inputs, binder grade system should be selected from the three grading systems built-in the software, Superpave performance grade, conventional penetration grade, or conventional viscosity grade.

For HMA characterization, level 1, laboratory-measured dynamic modulus values at a minimum of three temperatures and three frequencies are needed. For Levels 2 and 3, predictive models are used instead to estimate the dynamic moduli at the target temperature and frequency. Two different $\mathrm{E}^{*}$ predictive models were built in MEPDG software for levels 2 and 3. The first model is the NCHRP 1-37A viscosity $(\eta)$ based model, while the other is the NCHRP1-40D G*-based model. The structure, and the formation of the two $\mathrm{E}^{*}$ predictive models are detailed in ElBadawy et al., (2012); ARA, (2004); Sholar et al., (2005) and Witczak et al., (2007). The major difference between the two models is the binder stiffness term (ElBadawy et al., 2012).

As well, the MEPDG software adopted three hierarchical levels for the characterization of the unbound base/subbase materials and subgrade soil (AASHTO, 2008; El-Badawy et al., 2011b). For level 1, resilient modulus should be determined through laboratory testing to get the $\mathrm{k}_{1}, \mathrm{k}_{2}$, and $\mathrm{k}_{3}$ coefficients by the application of the testing data to the universal model shown in Equation (5).

$M_{r}=k_{1} p_{a\left(\frac{\theta}{p_{a}}\right)^{k x}}\left(\frac{x_{0 c t}+1}{p_{a}}\right)^{k s}$

Where,

$\mathrm{M}_{\mathrm{r}}=$ resilient modulus (psi)

$\Theta=$ bulk stress $=\sigma_{1}+\sigma_{2}+\sigma_{3}$

$\sigma_{1}=$ major principal stress

$\sigma_{2}=$ intermediate principal stress

$\sigma_{3}=$ minor principal stress

$\tau_{\text {oct }}=$ octahedral shear stress

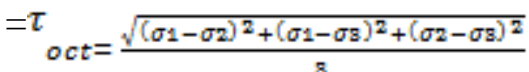

$\mathrm{p}_{\mathrm{a}}=$

atmospheric pressure $=101 \mathrm{kPa}(14.7 \mathrm{psi})$

$\mathrm{k}_{1}, \mathrm{k}_{2}, \mathrm{k}_{3}=$ regression constants

Level 2 is the case where resilient modulus can be determined through the correlations with some other material properties e.g., CBR or R-value. For example the program uses the Equation (6) to correlate $\mathrm{Mr}$ with the CBR (AAHTO 2008):

$\mathrm{Mr}=2555(\mathrm{CBR})^{0.65}$

In level 3, typical default values of layer modulus as a function of soil classification can be chosen from the database of the states departments or highway agencies.

Number of researchers (e.g., Ahn et al, 2011; Swan et al, 2008; Hoerner et al, 2007 ; and El-Badawy et al., 2011a) investigated the impact of traffic input level on pavement performance. In summary, it was found in the literature that large errors for the predicted distresses particularly in longitudinal cracking are 
resulted when level 3 is used instead of level 1. Little prediction errors in rutting are resulted when level 3 is used. ElBadawy et al. (2011a) found that the predicted international roughness index was not affected by the changing of the traffic input level.

Similarly, significant impact on the pavement performance predictions in terms of rutting was found in the literature by ElBadawy et al. (2012) when the input level of the binder characterization was altered.

This study evaluates the influence of changing the input level of only the unbound materials on the pavement performance.

\section{Research Methodology and Inputs}

To investigate the influence of unbound materials input level on the pavement performance, computer simulation runs using MEPDG were conducted for 10 years of service life. Average Annual Daily Traffic (AADT) of 1500 vehicles per day with a growth rate of $2 \%$, which is equivalent to 5,699,120 Equivalent Single Axle Loads (ESALS) at the end of the 10 years design life, was used for all runs. The simulation runs ware conducted using three weather stations represent different climatic regions in Egypt. Theses weather stations were Alexandria, Cairo, and Aswan. More details regarding the climatic data files used for the runs can be found in Elshaeb et al 2014 and Elsaheb 2015.

A typical conventional flexible pavement system with the layers shown in Figure 1 was used for all simulation runs.

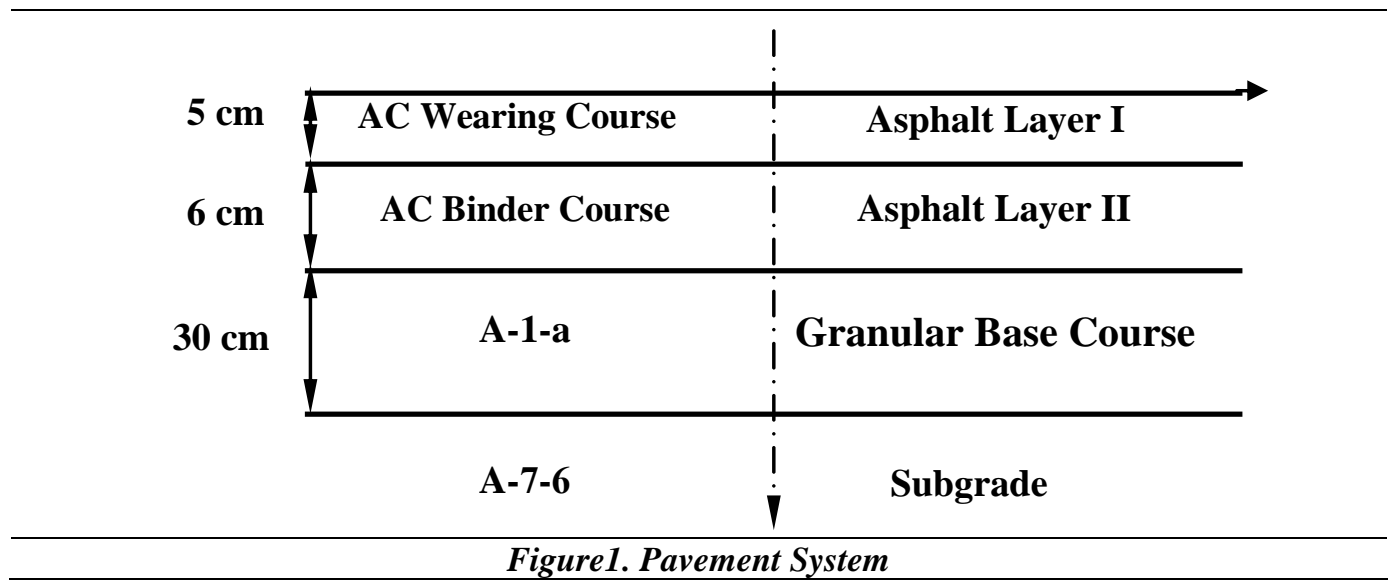

The Asphalt Concrete (AC) layers' properties as well as the binder properties required for MEPDG are summarized in Table 1.

Table 1. Properties of Asphalt Binder and HMA layers

\begin{tabular}{|l|c|c|}
\hline \multicolumn{1}{|c|}{ Property } & AC Wearing Course & AC Binder Course \\
\hline Thickness, in. (cm) & $2(5)$ & $2.4(6)$ \\
\hline Cumulative Retained 3/4 inch Sieve & 11.7 & 18.1 \\
\hline Cumulative Retained 3/8 inch Sieve & 23.7 & 35.7 \\
\hline Cumulative Retained \#4 inch Sieve & 49.7 & 69.1 \\
\hline \% Passing \#200 Sieve & 4.2 & 1.2 \\
\hline Initial Mix Air Voids (\% Va) & 7.0 & $\mathbf{8 . 0}$ \\
\hline Effective Binder content by Volume (\% $\left.\mathbf{V}_{\text {beff }}\right)$ & 11.0 & 10.2 \\
\hline Total Unit Weight, pcf $\left(\mathbf{t} / \mathbf{m}^{3}\right)$ & $141.82(2.27)$ & $\mathbf{1 4 2 . 4 4 ( 2 . 2 8 )}$ \\
\hline Penetration Grade of AC Binder & $60-70$ & $60-70$ \\
\hline
\end{tabular}


For base course, a $30 \mathrm{~cm}$ crushed stone layer of AASHTO class A-1-a was used with the properties specified in Table 2. Three input levels were investigated for the base layer. For the typical pavement system, level 1 data for the resilient modulus based on measured laboratory values $\left(\mathrm{k}_{1}, \mathrm{k}_{2}\right.$, and $\mathrm{k}_{3}$ elastic response coefficients) were used for the first set of MEPDG runs. The second set of computer simulation runs were conducted using the laboratory measured California Bearing Ratio (CBR) values of the granular base material. The final set of runs, utilized default resilient modulus values of the unbound base material based on the AASHTO class as recommended by the MEPDG. The subgrade layer properties are specified in Table 3.

Table 2. Properties of the Unbound Base Material

\begin{tabular}{|c|c|}
\hline Property & Granular Base \\
\hline Thickness, in. (cm) & $12(30)$ \\
\hline CBR (\%) & 100 \\
\hline Passing \#200 Sieve (\%) & 11.0 \\
\hline Passing \#100 Sieve (\%) & 14.0 \\
\hline Passing \#50 Sieve (\%) & 17.0 \\
\hline Passing \#40 Sieve (\%) & 18.0 \\
\hline Passing \#30 Sieve (\%) & 21.0 \\
\hline Passing \#16 Sieve (\%) & 26.0 \\
\hline Passing \#8 Sieve (\%) & 33.0 \\
\hline Passing \#4 Sieve (\%) & 47.0 \\
\hline Passing 3/8 inch Sieve (\%) & 70.0 \\
\hline Passing $1 / 2$ inch Sieve $(\%)$ & 88.0 \\
\hline Passing $3 / 4$ inch Sieve (\%) & 96 \\
\hline Passing 1 inch Sieve (\%) & 100 \\
\hline Liquid Limit & 18.0 \\
\hline Plasticity Index & 3.0 \\
\hline Material Type According to AASHTO Classification & A-1-a \\
\hline Maximum Dry Density, pcf $\left(t / \mathbf{m}^{3}\right)$ & $134.84(2.16)$ \\
\hline Resilient Modulus Regression Coefficients & $k_{1}=1097.35, k_{2}=0.83, k_{3}=-0.45$ \\
\hline
\end{tabular}

Table 3. Properties of the Subgrade Soil

\begin{tabular}{|c|c|}
\hline Property & Subgrade Soil \\
\hline Passing \#200 Sieve (\%) & 79.1 \\
\hline Passing \#80 Sieve (\%) & 84.9 \\
\hline Passing \#40 Sieve (\%) & 88.8 \\
\hline Passing \#10 Sieve (\%) & 93.0 \\
\hline Passing \#4 Sieve (\%) & 94.9 \\
\hline Passing 3/8 inch Sieve (\%) & 96.9 \\
\hline Passing $1 / 2$ inch Sieve $(\%)$ & 97.5 \\
\hline Passing $3 / 4$ inch Sieve $(\%)$ & 98.3 \\
\hline Passing 1 inch Sieve (\%) & 98.3 \\
\hline Passing $1 \frac{1}{2}$ inch Sieve (\%) & 99.3 \\
\hline Passing 2 inch Sieve (\%) & 99.6 \\
\hline Passing 3 1/2 inch Sieve (\%) & 99.9 \\
\hline Liquid Limit & 51.0 \\
\hline Plasticity Index & 30 \\
\hline Material Type According to AASHTO Classification & A-7-6 \\
\hline Maximum Dry Density, pcf $\left(t / \mathrm{m}^{3}\right)$ & $97.7(1.56)$ \\
\hline
\end{tabular}




\section{Results and Discussion}

A total of 9 MEPDG simulation runs were conducted. Each run for the level 1 analysis lasted for approximately 18 hours while each level 2 or 3 run took about15 minutes to compete. Despite the input level, MEPDG computes the pavement response using the same methodology. MEPDG predicts rutting, bottom-up fatigue cracking, longitudinal cracking, and International Roughness Index (IRI) over the service life of the pavement. All distresses were computed from the program at two different reliability levels of $50 \%$ and $90 \%$. Figure 2 shows a comparison of the predicted rutting at $90 \%$ reliability level as a function of the pavement age for Cairo climate at the different investigated $\mathrm{M}_{\mathrm{r}}$ input levels.

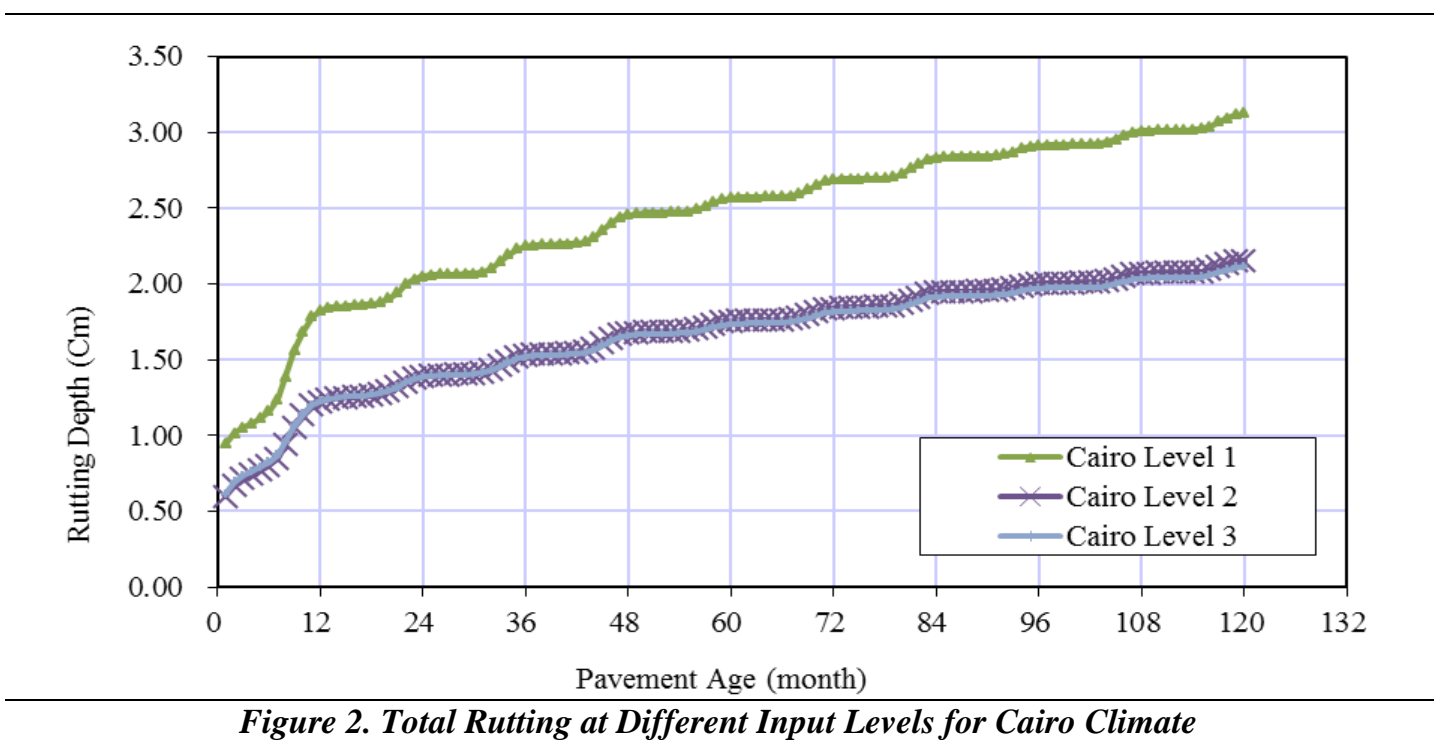

Figure 2. Total Rutting at Different Input Levels for Cairo Climate

A summary of the results of the performed runs is given in Table 4. Results presented in the table show variation in pavement performance indicators as the input level changes.

Table 4. Pavement distresses for Different Input Levels at Egypt Representative Weather Stations at the end of Design life.

\begin{tabular}{|c|c|c|c|c|c|c|c|c|c|}
\hline \multirow{2}{*}{$\overbrace{0}^{3}$} & \multirow[t]{2}{*}{$\begin{array}{l}\text { Input } \\
\text { Level }\end{array}$} & \multicolumn{2}{|c|}{$\begin{array}{c}\text { Longitudinal } \\
\text { Cracking (m/km) }\end{array}$} & \multicolumn{2}{|c|}{$\begin{array}{c}\text { Alligator } \\
\text { Cracking (\%) }\end{array}$} & \multicolumn{2}{|c|}{ Rutting (cm) } & \multicolumn{2}{|c|}{ IRI (m/km) } \\
\hline & & $\mathbf{R}=\mathbf{5 0 \%}$ & $\mathbf{R}=90 \%$ & $\begin{array}{c}\mathbf{R}= \\
\mathbf{5 0 \%}\end{array}$ & $R=90 \%$ & $\mathbf{R}=\mathbf{5 0 \%}$ & $\mathbf{R}=90 \%$ & $\mathrm{R}=\mathbf{5 0 \%}$ & $\mathbf{R}=90 \%$ \\
\hline \multirow{3}{*}{ 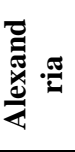 } & Level 1 & 838.20 & 1396.48 & 24 & 42.11 & 2.177 & 2.893 & 1.82 & 2.46 \\
\hline & Level 2 & 1.43 & 172.17 & 3.42 & 21.34 & 1.450 & 1.938 & 1.46 & 1.99 \\
\hline & Level 3 & 6.39 & 284.60 & 5.34 & 23.43 & 1.519 & 2.040 & 1.49 & 2.04 \\
\hline \multirow{3}{*}{ Uే } & Level 1 & 981.53 & 1543.53 & 28.2 & 46.31 & 2.601 & 3.447 & 1.96 & 2.63 \\
\hline & Level 2 & 1.54 & 176.62 & 3.3 & 21.17 & 1.730 & 2.350 & 1.51 & 2.06 \\
\hline & Level 3 & 6.62 & 287.95 & 5.33 & 23.42 & 1.798 & 2.451 & 1.54 & 2.11 \\
\hline \multirow{3}{*}{ 空 } & Level 1 & 1037.77 & 1601.19 & 28.3 & 46.41 & 2.682 & 3.561 & 1.96 & 2.64 \\
\hline & Level 2 & 1.68 & 182.17 & 3.31 & 21.19 & 1.920 & 2.637 & 1.54 & 2.10 \\
\hline & Level 3 & 7.08 & 293.95 & 5.42 & 23.52 & 1.989 & 2.705 & 1.57 & 2.15 \\
\hline
\end{tabular}


It can be seen from the data in the table that level 1 input yielded the highest values of longitudinal and alligator cracking. The difference in results from level 1 to level 2 and level 3 of both forms of fatigue cracking (alligator and longitudinal)are significant. For example, for Alexandria climate, longitudinal cracking for level 1 is 8 times that of level 2 and 5 times that of level 3. While alligator cracking in Aswan yielded from level 1 is 2.19 times that of level 2 and 1.97 times that of level 3. It can also be concluded that fatigue cracking values for Aswan are higher than Cairo and both Aswan and Cairo are higher than Alexandria. The data in Table 4 also shows that rutting values for level 1 input are1.5 times the rutting values of level 2 and 1.4 times values of level 3 for Cairo. Again, the rutting values for Aswan are higher than Cairo and both Aswan and Cairo are higher than Alexandria. The IRI results showed that IRI is higher for level 1 by $124 \%$ and $121 \%$ than levels 2 and 3 respectively. The IRI values for Aswan are higher than Cairo and both Aswan and Cairo are higher than Alexandria. These results indicate that for all practical purposes $M_{r}$ input levels 2 and 3 yield very similar performance while $\mathrm{M}_{\mathrm{r}}$ level 1 input yield very high distresses compared to levels 2 and 3 . For all values of performance indicators the hottest climate (Aswan) yielded higher distresses compared the Cairo and Alexandria Climate.

Table 5 presents the predicted rutting for each layer individually. This data show contribution of each layer to the total rutting for each of the input levels investigated. The data show significantly lower rutting values in the granular base layer compared to the $\mathrm{AC}$ and subgrade layers, for levels 2 and 3. For level 1, the predicted base layer rutting is almost comparable to the subgrade layer rutting and much higher compared to levels 2 and 3. This is not rational, as one should expect lower amount of rutting in the granular base layer because of the grain to grain interlocking action. Further, the contribution of the AC layer to the total rutting is the highest which may indicate inferior AC layer quality. The predicted AC layer rutting based on level $1 \mathrm{M}_{\mathrm{r}}$ data is also higher compared to the values based on levels 2 and 3 for all investigated weather conditions. It should be noted that the current global calibration factors in the MEPDG were based on level 3 unbound material characterization.

Table 5. Rutting of Sublayers for Different Input Levels at Egypt Representative Weather Stations at the End of Design Life

\begin{tabular}{|c|c|c|c|c|c|}
\hline \multirow{2}{*}{ City } & \multirow{2}{*}{ Input Level } & \multicolumn{4}{|c|}{ Predicted Rutting $(\mathrm{cm})$} \\
\hline & & AC Layer & Base Layer & Subgrade & Total \\
\hline \multirow{3}{*}{ 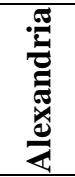 } & Level 1 & 1.171 & 0.868 & 0.855 & 2.894 \\
\hline & Level 2 & 0.794 & 0.279 & 0.866 & 1.939 \\
\hline & Level 3 & 0.810 & 0.342 & 0.887 & 2.039 \\
\hline \multirow{3}{*}{ שֶ. } & Level 1 & 1.658 & 0.938 & 0.852 & 3.448 \\
\hline & Level 2 & 1.216 & 0.289 & 0.843 & 2.348 \\
\hline & Level 3 & 1.232 & 0.354 & 0.864 & 2.450 \\
\hline \multirow{3}{*}{$\begin{array}{l}\text { 五 } \\
\text { 离 }\end{array}$} & Level 1 & 1.763 & 0.950 & 0.847 & 3.560 \\
\hline & Level 2 & 1.484 & 0.326 & 0.827 & 2.637 \\
\hline & Level 3 & 1.496 & 0.361 & 0.848 & 2.705 \\
\hline
\end{tabular}




\section{Summary and Conclusions}

A total of 9 MEPDG computer simulation runs were conducted using a typical pavement section used in Egypt. The three hierarchal input levels for the unbound granular base layer were used in this research. The MEPDG runs were conducted at three climatic conditions represented by Alexandria, Cairo, and Aswan. Based on the results and analyses of this research the following conclusions were drawn:

- The input level of the unbound materials has a significant influence on the MEPDG predicted performance.

- Level 1 unbound material characterization input yielded significantly higher rutting and cracking compared to Levels 2 and 3.

- Levels 2 and 3 yielded significantly lower rutting values in the granular base layer compared to the AC and subgrade layers whereasfor level 1 , the predicted base layer rutting was almost comparable to the subgrade layer rutting and much higher compared to levels 2 and 3.

- For all practical purposes, the MEPDG predicted performance indicators using levels 2 and 3 input levels for the unbound base layer were relatively similar.

- The results showed that, despite the input level for the unbound material characterization, the hotter the climate, the larger the predicted distress.

- Finally, it is recommended to calibrate the MEPDG distress models before using level 1 input for unbound material characterization.

\section{References}

[1] AASHTO (2008) MechanisticEmpirical Pavement Design Guide: A Manual of Practice, Interim Edition, American Association of Highways and Transportation Officials.
[2] Ahn, S., Kandala, S., Uzan, J., and El-Basyouny M. (2011) Impact of Traffic Data on the Pavement Distress Predictions using the Mechanistic Empirical Pavement Design Guide (MEPDG), Road Materials and Pavement Design, Vol. 12/1, pp. 195-216.

[3] ARA, Inc., ERES Consultants Division (2004) Guide for Mechanistic-Empirical Design of New and Rehabilitated Pavement Structures, NCHRP 1-37A Final Report, Transportation Research Board, National Research Council, Washington, D.C.

[4] El-Badawy, S., Bayomy, F., and Awed, A. (2012) Performance of MEPDG Dynamic Modulus Predictive Models for Asphalt Concrete Mixtures: Local Calibration for Idaho. J. Mater. Civ. Eng. Vol. 24 (11), PP. (1412-1421).

[5] El-Badawy, S., Bayomy, F., and Fugit, S. (2011a) Traffic Characteristics and their Impact on Pavement Performance for the Implementation of the MechanisticEmpirical Pavement Design Guide in Idaho, Paper 12-1886, $91^{\text {th }}$ Annual Meeting, Transportation Research Board, Washington, D.C.

[6] El-Badawy, S., Bayomy, F., and Miller, S. (2011b) Prediction of the Subgrade Resilient Modulus for the Implementation of the MEPDG in Idaho. Proceeding of Geo-Frontiers: Advances in Geotechnical Engineering, ASCE, pp. 4762-4772.

[7] Elshaeb, M., (2015) "Climatic Characterization and its Influence upon Flexible Pavement Performance in Egypt using MEPDG,".MS.C. Thesis, Mansoura University, Mansoura, Egypt.

[8] Elshaeb, M., El-Badawy, S., ElSayed, S., (2014) "Development and Impact of the Egyptian Climatic Conditions on Flexible Pavement 
Performance,". American Journal of Civil Engineering and Architecture, Vol. 2 ,Issue 3PP. 115-121, DOI: 10.12691/ajcea-2-3-4.

[9] George, K. P. (2004) Prediction of resilient modulus from soil index properties. Final Report, Department of Civil Engineering, University of Mississippi, 71 pages.

[10] Heukelom, W., and Klomp, A. (1962) Dynamic testing as a means of controlling pavements during and after construction, proceedings of the first International Conference on Structural Design of Asphalt Pavements, University of Michigan, USA.

[11] Hoerner, T., Zimmerman, K., Smith, K., and Cooley, L. (2007) Mechanistic-Empirical pavement Design guide Implementation Plan, Report No. SD2005-01, Applied Pavement technology, Inc., Urbana, IL.

[12] Janoo, V.C., Bayer, J.J., Durell, G.D., and Smith, C.E. (1999) Resilient Modulus for New Hampshire Subgrade Soils for Use in Mechanistic AASHTO Design, Special Report 99-14.

[13] Mohammad, L. N., Huang, B., Puppala, A J. and Allen, A. (1999) Regression model for resilient modulus of subgrade soils, Transportation Research Record, 1442: 47-54.

[14] Sholar, G., Roque, R., and Birgisson, B. (2005) Evaluation of a predicted dynamic modulus for Florida mixtures. Transportation Research Record 1929, Transportation Research Board, pp. 200-207, Washington, D.C.
[15] Swan, D.J., Tardif, R., Hajek, J., and Hein D. K. (2008) Development of Regional Traffic Data for the Mechanistic-Empirical Pavement Design Guide. Transportation Research Record: Journal of the Transportation Research Boarded, No. 2049, Transportation Research Boarded of the National Academies, pp. 54-62, Washington, D.C.

[16] The Asphalt Institute (1982) Research and development of the Asphalt institute's thickness design manual, $9^{\text {th }}$ edition, Research report No. 82-2, pages 60 .

[17] Thompsom, M. R., and LaGrow, T., (1988) A proposed Conventional Flexible Pavement Thickness Design Procedure, Civil Engineering Studies, Transportation Engineering Series No. 55, University of Illinois at Urbana-Champaign.

[18] Witczak, M., El-Basyouny, M., and El-Badawy, S. (2007) Incorporation of the new (2005) $\mathrm{E}^{*}$ predictive model in the MEPDG. NCHRP 140D Inter-Team Technical Report, Arizona State Univ., Tempe, AZ.

[19] Witczak, M.W., Andrei, D., and Houston, W.N., (2000) Resilient modulus as function of soil moisture - summary of predictive models. Development of the 2002 guide for the development of new and rehabilitated pavement structures, NCHRP 1-37 A, Inter team technical report (Seasonal 1).

[20] Woolstrum, G., (1990) Dynamic Testing of Nebraska Soils and Aggregates Transportation Research Record No. 1278, Transportation Research Board, pp. 27-34. 